\title{
Heart rate conditioning in goldfish (Carassius auratus) and not in rainbow trout (Salmo gairdneri)
}

\author{
RICHARD T. ERSPAMER \\ Western Washington State College, Bellingham, Washington 98225
}

and

MERLE E. MEYER

University of Florida, Gainesville, Florida 32611

\begin{abstract}
The heart rate response for goldfish, Carassius auratus, and rainbow trout, Salmo gairdneri, was compared with CS, US, and pseudoconditioning controls within a respondent conditioning paradigm. Goldfish, but not rainbow trout, showed a differential CHR (bradycardia) in the experimental condition in contrast to the controls.
\end{abstract}

Respondent conditioning of the heart rate has been reported in a few species of fish. Otis, Cerf, and Thomas (1957) conditioned the heart rate (CHR) in goldfish 'Carassius auratus) and, subsequently, Bernstein (1961, 1962), McCleary (1960), and McCleary and Bernstein (1959) used the CHR in goldfish to investigate various risual functions. Furthermore, the CHR has also been ssed to determine auditory thresholds in goldfish Offutt, 1968), in tautogs (Tautoga onitus) (Offutt, 1971), and in codfish (Gadus morrhua) (Buerkle, 1967). These studies showed a reliable CHR (bradycardia) in he three species in fewer than 40 trials.

The heart of fish (except the hagfish) is innervated by he vagus, and it is assumed that the cardiac vagus :ontains cholinergic fibers (Randall, 1970). For :xample, the application of acetylcholine results in radycardia, as does the stimulation of the vagus, and tropine blocks the deceleration of the cardiac activity. In the other hand, Yamauchi and Burnstock (1968) and jannon and Burnstock (1969) reported excitatory drenergic fibers innervated the trout heart. While these ibers have not been directly stimulated, it is suggestive hat acceleration is a possible CHR in trout.

The purpose of the present experiment was twofold. he first objective was to investigate heart rate condiioning in goldfish and in rainbow trout and to compare he CHR of these species. As none of the heart rate onditioning studies with fish has reported appropriate xperimental control data, the second purpose was to pproximate the conditioning procedures used by revious investigators and to add additional control onditions (Rescorla, 1967).

This research is based upon a thesis submitted to the Departient of Psychology, Western Washington State College, in artial fulfillment of the requirements for the MS degree by the nior author. Requests for reprints should be sent to Merle E. eyer, Department of Psychology, University of Florida, ainesville, Florida 32611.

\section{METHOD}

\section{Subjects}

The subjects were 12 rainbow trout (Salmo gairdneri) that were acquired from Whatcom Falls Hatchery in Bellingham, Washington, and 12 goldfish (Carassius auratus) acquired from Santiam Aquarium in Brownsville, Oregon. The fish $(15-20 \mathrm{~cm}$ long) were housed in a 300-liter aquarium measuring $120 \mathrm{x}$ $120 \times 120 \mathrm{~cm}$ for 1 to 4 days prior to experimentation. The aquarium temperature was approximately $12^{\circ} \mathrm{C}$. They were maintained on a photoperiod which approximated the normal seasonal environment; illumination occurred from 7:00 a.m. until 6:00 p.m.

\section{Apparatus}

A fish was placed in a clear plastic tank $27 \mathrm{~cm}$ long $\times 6 \mathrm{~cm}$ wide $x 14 \mathrm{~cm}$ deep. The plastic tank was located inside a $45 \mathrm{~cm}$ long $\times 14 \mathrm{~cm}$ wide $\times 17 \mathrm{~cm}$ deep electrically shielded compartment. A constant . 5 -liter $/ \mathrm{min}$ flow of charcoal-filtered water was circulated through the tank to provide an adequate supply of oxygenated water. Six 24-V dc lamps, three located on either side of the shielded compartment, served as the conditioned stimulus (CS). The unconditioned stimulus (US) was a 1.5-sec $.050-\mathrm{mA} \mathrm{dc}$ electric shock delivered through alligator-clip electrodes. This intensity of shock resulted in a reliable flinch or startle response in both species of fish. A polygraph was used to record the heart rate.

\section{Procedure}

The active electrode was fastened to the pectoral fin, the indifferent electrode to the tail fin, and the ground electrode was connected to the dorsal fin. The fish was placed in the plastic tank and allowed to habituate for a period of $5 \mathrm{~min}$. Except for the US control, all conditions consisted of 41 trials. A variable intertrial interval (V-ITI) of $70 \mathrm{sec}$ was used for all treatment conditions except the pseudoconditioning control.

Previous experiments used a brief CS for training and a longer CS for testing. The present experiment approximated that situation using 10- and 20-sec test CSs to assess the influence of the length of the CS upon conditioning.

The heart rate was measured during the last $10 \mathrm{sec}$ of the baseline (BS) just prior to the CS period, and the first $10 \mathrm{sec}$ that immediately followed the CS period (P-CS). Data were collected and analyzed on test trials only.

\section{Treatment Conditions}

The CS-US treatment condition had three forms of CS 
presentation. There were 31 training trials $(1-9,12-19,22-19$, and 32-39) that consisted of a 4.5 -sec CS with the US during the last $1.5 \mathrm{sec}$, and four test trials with a 10 -sec CS period and four test trials with a 20 -sec CS and an US during the final 1.5 sec.

The control conditions consisted of: (1) a CS control that was identical to the CS-US treatment condition except that no US was present, (2) an US control that consisted of the presentation of the US without the CS, and (3) a pseudoconditioning control where the CSs and USs were presented such that one CS and US occurred within each trial time. There was no temporal relationship between the CS and US within a trial, and they occurred in random order.

\section{RESULTS AND DISCUSSION}

The Species by Treatment Conditions by Periods by Trials Blocks interaction from the analysis of variance was not statistically significant $(\mathrm{p}>.05)$. Within this analysis the CS length variable was confounded and was thus pooled by mean values in trial blocks. Even though the interaction was not significant, the experiment as designed dictated the testing of certain main effects. Consequently, certain multiple comparisons were made with a more stringent alpha level $(p<.01)$. Critical differences for the subsequent analyses were computed using the error term from the main analyses used to test the interaction (Lindquist, 1953) and the largest range value $(\mathrm{p}<.01)$ from Duncan's multiple-range test (Bruning \& Kintz, 1968).

\section{Analyses of the Goldfish Data}

The CS-US treatment condition yielded no significant differences in heart rate between the BS and P-US periods across trial blocks. However, the heart rate during the CS period was significantly lower $(p<.01)$ than during both BS and P-US periods within all trial blocks, and the CS heart rate of Trial Block 4 was significantly lower $(\mathrm{p}<.01)$ than Trial Blocks 1 and 2. These comparisons suggest that conditioning occurred, in that there was significant deceleration of heart rate during the CS period relative to the BS period, and the magnitude of this differential response increased as a function of trials.

Further analyses of the data with goldfish showed no significant differences $(p>.01)$ across trial blocks for the CS-only, US-only, and pseudocontrol treatment conditions. These comparisons suggest that there was no conditioning in the pseudocontrol treatment, that the CS was a neutral stimulus, and that there was no differential unconditioned heart rate response (UR). The CS heart rate for the CS-only and pseudocontrol conditions was not different; however, the CS heart rate for the CS-US treatment was significantly lower than both the CS-only and pseudocontrol for all trial blocks.

\section{Analyses of the Trout Data}

The trout data showed no significant differences in heart rate between periods within trial blocks and across trial blocks for any of the treatment conditions. These analyses indicate that no conditioning occurred and that a cardiac UR was not found in trout.

\section{DISCUSSION}

This experiment confirmed the findings of previous investigators concerning conditioning of heart rate in goldfish (Bernstein, 1961, 1962; McCleary, 1960; McCleary \& Bernstein, 1959; Otis et al., 1957). The CS data indicated that conditioning occurred rather than in response to the CS alone or noncontingent presentation of the CS and US. There was, however, no evidence of heart rate conditioning in trout.

The exact nature of the cardiac response rate varies among species as a function of such variables as touch, electric shock, salinity, and temperature changes. Some species of fish show bradycardia to many stimuli, while other species require specific stimuli (Randall, 1970). The results of the present study demonstrated conditioned bradycardia in goldfish with the pairing of a light (CS) and an electric shock (US), but not in trout. The lack of CHR in the trout may be a function of the CS and US used in these studies or may be a function of the trout's circulatory system and its innervation.

\section{REFERENCES}

Bernstein. J. J. Brightness discrimination following forebrain ablation in fish. Experimental Neurology, 1961, 3. 297-306.

BERNSTEIN. J. J. Role of the telencephalon in color vision in fish. Experimental Neurology. 1962, 6. 173-185.

Bruning. J. L.. \& Kintz. B. L. Computational handbook of statistics. Atlanta: Scott Foresman. 1968. P. 115-117.

Buerkle, U. An audiogram of the Atlantic cod, Gadus morrhua. Journal of Fisheries Research Board of Canada, 1967. 24. 2309-2319.

Gannon. B. J.. \& BuRnstock, G. Excitatory adrenergic innervation of the tish heart. Comparative Biochemical Physiology" 1969. 29. 765-773.

Lindquist. E. F. Design and analysis of experiments in psychology and education. Boston: Houghton Mifflin. 1953. P. 243.

MCCleary. R. A. Type response as a factor in interocular transfer in the fish. Journal of Comparative and Physiological Psychology, 1960, 53, 311-321.

Mc Cleary, R. A.. \& Bernstein, J. J. A unique method for control of brightness cues in study of color vision in fish. Physiological Zoology, 1959, 32. 248-292.

Offutt. G. C. Auditory response in the goldfish. Journal of Auditory Research, 1968, 8, 391-400.

Offutt, G. C. Response of the tautog (Tautog onitus) to acoustic stimuli measured by classically conditioned heart rate. Conditioned Reflex, 1971, 6, 205-214.

Otis. L. S., Cerf, J. A..\& Thomas, G. J. Conditioned inhibition of respiration and heart rate in the goldfish. Science. 1957. 126. 203-264.

Randall. D. J. The circulatory system. In W. S. Hoar \& D. J. Randall (Eds.). Fish physiology (Vol. 4). New York: Academic Press. 1970.

Rescorla, R. A. Pavlovian conditioning and its proper control procedures. Psychological Review', 1967, 74. 71-80.

Yamauchi. A.. \& Burnstock. G. An electromicroscopic study on the innervation of the trout heart. Journal of Comparative Neurology'. 1968, 132, 567-588.

(Received for publication August 8, 1977.) 